\title{
Dynamic contrast-enhanced near-infrared spectroscopy using indocyanine green on moderate and severe traumatic brain injury: a prospective observational study
}

\author{
Mario Forcione $e^{1,2} \wedge$, Kamal Makram Yakoub ${ }^{1} \wedge$, Antonio Maria Chiarelli $^{3} \wedge$, David Perpetuini ${ }^{3} \wedge$, \\ Arcangelo Merla ${ }^{3} \wedge$, Rosa Sun ${ }^{1}$, Piotr Sawosz ${ }^{4} \wedge$, Antonio Belli ${ }^{1,2}$, David James Davies ${ }^{1,2}$ \\ ${ }^{1}$ University Hospitals Birmingham NHS Foundation Trust, National Institute for Health Research Surgical Reconstruction and Microbiology \\ Research Centre (NIHR-SRMRC), Mindelsohn Way, Birmingham, UK; ${ }^{2}$ University of Birmingham, Neuroscience \& Ophthalmology Research \\ Group, Institute of Inflammation \& Ageing, College of Medical and Dental Sciences, Edgbaston, Birmingham, UK; ${ }^{3}$ University G. D'Annunzio of \\ Chieti-Pescara, Institute for Advanced Biomedical Technologies, Department of Neuroscience, Imaging and Clinical Sciences, Chieti, Italy; ${ }^{4} \mathrm{Nalecz}$ \\ Institute of Biocybernetics and Biomedical Engineering, Polish Academy of Sciences, Trojdena 4, Warsaw, Poland \\ Correspondence to: Mario Forcione. University Hospitals Birmingham NHS Foundation Trust, Mindelsohn Way, Birmingham, B15 2TH, UK. Email: \\ mxf610@student.bham.ac.uk.
}

\begin{abstract}
Background: The care given to moderate and severe traumatic brain injury (TBI) patients may be hampered by the inability to tailor their treatments according to their neurological status. Contrast-enhanced near-infrared spectroscopy (NIRS) with indocyanine green (ICG) could be a suitable neuromonitoring tool.

Methods: Monitoring the effective attenuation coefficients (EAC), we compared the ICG kinetics between five TBI and five extracranial trauma patients, following a venous-injection of $5 \mathrm{~mL}$ of $1 \mathrm{mg} / \mathrm{mL}$ ICG, using two commercially available NIRS devices.

Results: A significantly slower passage of the dye through the brain of the TBI group was observed in two parameters related to the first ICG inflow into the brain $(\mathrm{P}=0.04 ; \mathrm{P}=0.01)$. This is likely related to the reduction of cerebral perfusion following TBI. Significant changes in ICG optical properties minutes after injection $(\mathrm{P}=0.04)$ were registered. The acquisition of valid optical data in a clinical environment was challenging.

Conclusions: Future research should analyze abnormalities in the ICG kinetic following brain trauma, test how these values can enhance care in TBI, and adapt the current optical devices to clinical settings. Also, studies on the pattern in changes of ICG optical properties after venous injection can improve the accuracy of the values detected.
\end{abstract}

Keywords: Near-infrared spectroscopy (NIRS); traumatic brain injury (TBI); indocyanine green (ICG); cerebral perfusion; blood-brain barrier (BBB)

Submitted Jun 08, 2020. Accepted for publication Jul 08, 2020.

doi: $10.21037 /$ qims-20-742

View this article at: http://dx.doi.org/10.21037/qims-20-742

^ ORCID: Mario Forcione, 0000-0002-4045-8011; Kamal Makram Yakoub, 0000-0001-7697-2453; Antonio Maria Chiarelli, 0000-00025347-8417; David Perpetuini, 0000-0003-1903-0501; Arcangelo Merla, 0000-0003-1111-6255; Piotr Sawosz, 0000-0002-0697-3036; Antonio Belli, 0000-0002-3211-9933. 


\section{Introduction}

Over the last decade, the burden of global neurotrauma has been on the rise (1). The efficacy of the care given to these patients has been called into question: a randomized clinical trial to test hypothermia therapy was terminated early due to its poor outcomes (2); Cooper et al. reported that performing early decompressive craniectomies for the treatment of intracranial hypertension did not enhance patient outcomes (3), while Hutchinson et al. reported a lower mortality rate in patients who undertook 'last resort' decompressive craniectomies, but only modest improvement to outcomes (4). One of the main differences between the studies from Cooper et al. and the one from Hutchinson et al. is that, while in the former the decompressive craniectomy was performed as one of the first therapeutic interventions, in the latter it was one of the last, made following other unsuccessful interventions. This may lead one to think that only a portion of those who had been under surgery in the study of Cooper et al. would have found the decompressive craniectomy beneficial, while the others could have received a more conservative treatment.

Chesnut et al. suggested that the lack of subtypeclassification in recruited TBI patients may be responsible for the limited improvements observed (5). This is linked fundamentally to limitations in injury burden stratification with current multimodal neuromonitoring tools (6): computed tomography (CT), for example, limits analysis to anatomical pathology without giving a clear picture of the complexity of post-injury pathophysiology (particularly at the bedside) including neuronal injury, perfusion deficiency, metabolic crisis, etc. $(7,8)$. The intracranial pressure (ICP) has fundamental limitations in that it is only a surrogate for cerebral perfusion, calculated via the differential between the pressure in the systemic vasculature and in the head. The ICP monitor limits analysis to the brain area in which it is inserted and cannot record different effects of trauma across the hemispheres (9). This motivates the adoption of detectable biomarkers in clinical neurotrauma, and the importance of coupling them to radiological patterns including magnetic resonance imaging (MRI), or other objective biological measurements into more robust and reliable biosignatures (10).

Cerebral perfusion and the integrity of the blood-brain barrier (BBB) can be impaired after brain trauma $(11,12)$. The analysis of these two parameters, either focally or globally, could comprise a more in-depth assessment of a patient's status and provide an alternative method for stratifying their severity. This can lead to:

(I) Development of novel treatments to reverse the directly observed pathology;

(II) Better direction of existing therapy towards individuals most likely to experience benefit.

Near-infrared spectroscopy (NIRS) can be a useful noninvasive, continuous, bedside neuromonitoring tool in the care of TBI patients (13). Studies on humans and animals have measured cerebral perfusion and vascular permeability after brain trauma by monitoring the kinetics of a contrast dye, indocyanine green (ICG), with NIRS devices (14-17). Unlike NIRS, other dynamic contrast-enhanced imaging techniques (i.e., CT, MRI) expose patients to ionizing radiation and/or cannot be performed continuously at the patients' bedsides (18). Currently, the ICG cerebral vascular kinetics monitored through contrast-enhanced NIRS in TBI patients remains to be fully investigated clinically.

ICG is a contrast dye with absorption and fluorescence properties in the NIR spectral range, and is commonly used in clinical practice (e.g., neuro-oncology; theranostic nanomedicine) (19-22). The ICG photon absorption is related to the dye concentration and to the nature of the solvent in which it is dissolved (23). In water, an increase in dye concentration drives changes in its absorption coefficient due to the progressive formation of ICG aggregates, which have an absorption peak at $690 \mathrm{~nm}$ wavelength, starting from the ICG monomers, which have a peak at $785 \mathrm{~nm}(19,23,24)$. In blood, ICG is bound by a large spectrum of proteins and lipids $(19,25)$. This binding process shifts the absorption peak to approximately $810 \mathrm{~nm}$ within a few seconds and stabilizes the dye's optical properties by interfering with the formation of ICG aggregates $(19,23,26)$.

Herein, we monitored the ICG kinetics in the brains of TBI and extracranial trauma (non-TBI) patients by measuring the effective attenuation coefficient (EAC) at multiple wavelengths, using two commercially available depth-resolved continuous-wave $(\mathrm{CW})$ and frequencydomain (FD)-NIRS devices (27-30). During the first ICG passage into the cerebral circulation, we hypothesized that we would observe an ICG optical signal for a longer period of time in the TBI group than in the non-TBI group, due to more impaired and attenuated brain perfusion in the former than in the latter. We also anticipated a prolonged ICG signal in the TBI group within a few minutes post-injection, due to leakage of the dye into the interstitial tissue of the parenchyma as a result of increased BBB permeability.

Furthermore, we compared the ICG absorption 


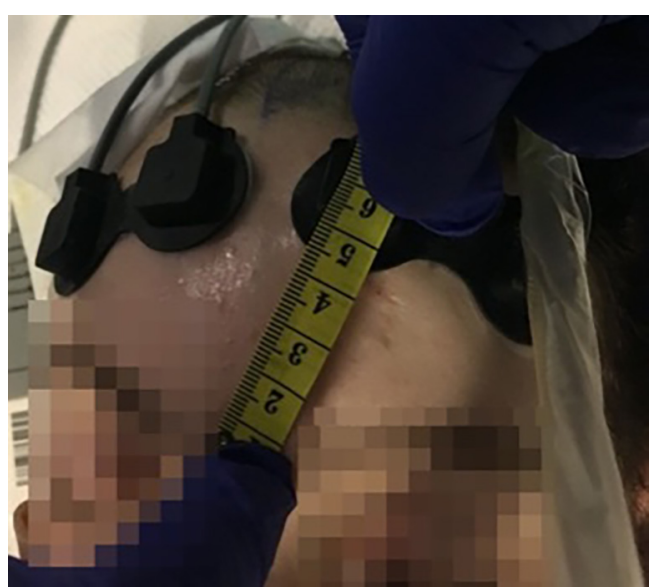

Figure 1 Representation of the positions of the NIRO-200NX probes on a TBI patient's forehead in ITU. A scale shows the distance in centimeters between one of the two probes and the patient's nasion. TBI, traumatic brain injury; ITU, intensive therapy unit.

properties at different wavelengths after injection by analyzing the slow changes in the EAC. We hypothesized that the highest level of photon absorption by the ICG would be at around $810 \mathrm{~nm}$, and no significant changes to ICG optical properties would be observed after a few seconds from the injections.

\section{Methods}

\section{Equipment}

A three wavelengths $(735 \mathrm{~nm}, 810 \mathrm{~nm}, 850 \mathrm{~nm}) \mathrm{CW}$-NIRS device, NIRO-200NX (Hamamatsu Photonics, Tokyo, Japan), and a two-wavelengths (690 nm, $830 \mathrm{~nm}$ ) FD-NIRS device, ISS-OxiplexTS ${ }^{\mathrm{TM}}$ (ISS Inc., Champaign, Illinois, USA) were used.

Both these devices employ a spatially resolved spectroscopy (SRS) NIRS approach with multiple sourcedetector distances $(31,32)$. The SRS approach permits enhanced sensitivity to deep (few $\mathrm{cm}$ ) structures and inference of the EAC, which is related to the exponential decay of the light signal with distance (27).

\section{Participants}

Five moderate and severe TBI (three males; mean age: 58) and five non-TBI patients (three males; mean age: 59), admitted to the ward or the intensive therapy unit (ITU) of the Queen Elizabeth Hospital Birmingham (UK) were enrolled into the study. Participants with suspected liver or kidney dysfunction were excluded from the study.

Four TBI patients were tested less than 14 days from injury (mean days: 8 ) while under sedation and one TBI patient, affected by chronic subdural hematoma, after more than three months while non-sedated. In all four acute TBI patients, the Glasgow Coma Scale (GCS) score at admission was 12 or lower, while in the other patient it was 15 . All TBI patients had a CT scan with signs of brain trauma. Three TBI patients had an ICP monitor at the time of observation, two of them had an ICP lower than $20 \mathrm{mmHg}$ and one patient had an ICP of $25 \mathrm{mmHg}$; one TBI patient passed away from the severity of injuries incurred acutely.

Non-TBI patients had GCS scores between 14 and 15 at admission; no signs of traumatic brain injury (TBI) were reported on the CT scan; non-TBI patients were all awake and orientated at the time of recording.

Two TBI and three non-TBI patients were scanned with the NIRO-200NX; three TBI and two non-TBI patients with the ISS-OxiplexTS ${ }^{\mathrm{TM}}$.

Initially, the data were acquired from 15 moderate and severe TBI (12 males; mean age: 30$)$ and 12 non-TBI patients ( 8 males; mean age: 48 ). However, the analysis had to be reduced to the aforementioned five moderate or severe TBI and five non-TBI patients because of the low signal-to-noise ratio in the rest of the sample.

\section{Data acquisition}

The study [Near Infra RED Cerebral Spectroscopy in the DIrection And early MONitoring of therapy in patients with traumatic brain injury (RED DIAMOND)] was approved by the East of England-Cambridge Central Research Ethics Board (Ref REC: 14/EE/0165; IRAS ID: 144979). Awake patients took part in this study after providing informed written consent. For those in an incapacitated state, a written consent form was received from the next of kin or from a person designated to give consent. The study conforms to the Declaration of Helsinki (as revised in 2013).

The optical probes were positioned on the patients' foreheads to monitor each hemisphere (Figure 1). The channels' positions were consistent across participants. If the signal was oversaturated, a bandage or a black sheet was applied on top of the probes to reduce ambient light. Awake participants were instructed to stay as still as they could.

An ICG powder for injection of $25 \mathrm{mg}$, Verdye 
A

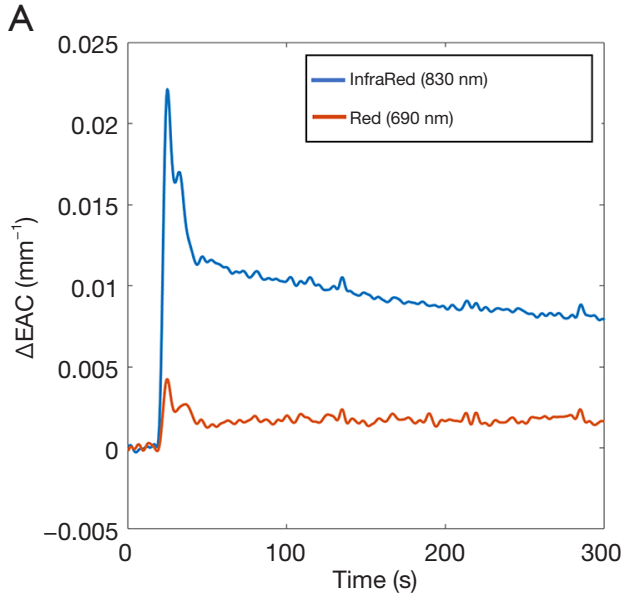

B

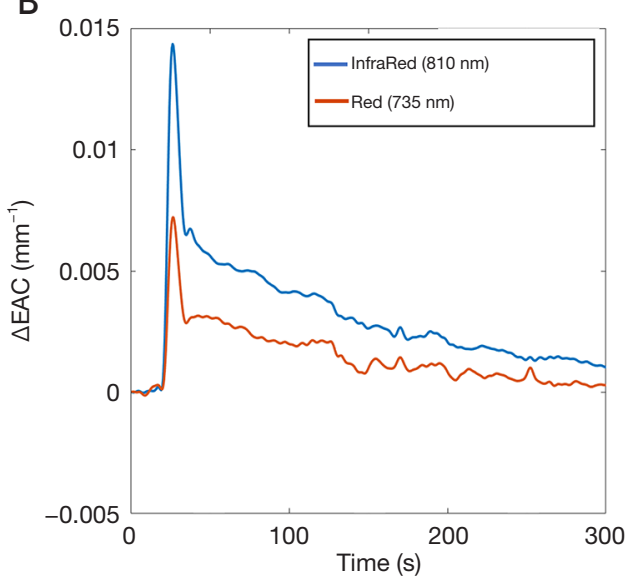

Figure 2 Examples of changes to the EAC evaluated with the (A) FD-NIRS ISS-OxiplexTSTM and the (B) CW-NIRS, NIRO-200NX. EAC, effective attenuation coefficient.

(Diagnostic Green GmbH, Aschheim, Germany), was mixed with $25 \mathrm{~mL}$ of water for injection. From this solution, two boluses of $5 \mathrm{~mL}$ of $1 \mathrm{mg} / \mathrm{mL}$ ICG were injected into the patients' venous peripheral cannulae or central lines. Following each injection, $5 \mathrm{~mL}$ of saline for injection was immediately flushed into the same cannula.

The optical signal was recorded for 2 and 10 minutes, respectively, before and after each ICG injection.

\section{NIRS data analysis}

\section{ICG's kinetic}

The ICG passage through the brain was assessed by evaluating the changes to EAC based on the CW light attenuation with distance (Figure 2) (27).

The phase shift registered by the FD-NIRS ISSOxiplexTS ${ }^{\mathrm{TM}}$ was ignored.

The EAC (expressed in $\mathrm{mm}^{-1}$ ) is proportional to the geometric mean of the absorption and reduced scattering coefficients of the volume investigated (33). Since the reduced scattering coefficient can be considered constant during the ICG dynamic, changes to EAC were considered directly related to the effect of the ICG absorption.

The EAC measured by the CW-NIRS and the FD-NIRS devices were combined: given their similar wavelengths, the changes to EAC at the wavelengths 735 and $690 \mathrm{~nm}$ (red) and the changes at 810 and $830 \mathrm{~nm}$ (infrared) were merged together.

In order to compare the EAC temporal dynamics among different subjects, the EAC curves were normalized (z-scored), and several parameters were evaluated. A first parameter to be evaluated was the width of the EAC curve. This width was estimated at $30 \%$ of the maximum EAC value (expressed in s, Figure 3A). Moreover, the EAC temporal dynamic was divided into three temporal ranges characterized by an early exponential increase, an early exponential decay, and a late linear decay (Figure 3B,C,D). The parameters associated with these three temporal ranges were two exponential rates of increase (positive value) and decay (negative value) and one rate of linear decay (negative value), all expressed in $\mathrm{s}^{-1}$. The late liner decay was considered for up to 5 minutes from injection due to the low ICG signal-to-noise ratio beyond this. The four extracted curve parameters were separately compared between the TBI and non-TBI groups using Student's $t$-test.

Similar to other contrast-enhanced imaging techniques (e.g., CT, MRI), the early exponential decay, the late linear decay and the width of the first passage of the dye bolus are indicative of cerebral perfusion; the early exponential decay was related to the ICG washing out which can be delayed if the ICG passed from the vascular space, where it was physiologically confined, to the interstitial brain tissue following BBB damage $(18,34)$. A translation of the ICG optical signal on TBI patients into absolute parameters of cerebral blood flow (CBF) and BBB may be inaccurate and unnecessary to answer the current clinical needs (14). As a result, the analysis of the ICG kinetic was limited to the differences in ICG optical signal between the TBI and non-TBI groups, without resolving this into $\mathrm{CBF}$ or $\mathrm{BBB}$ values. 

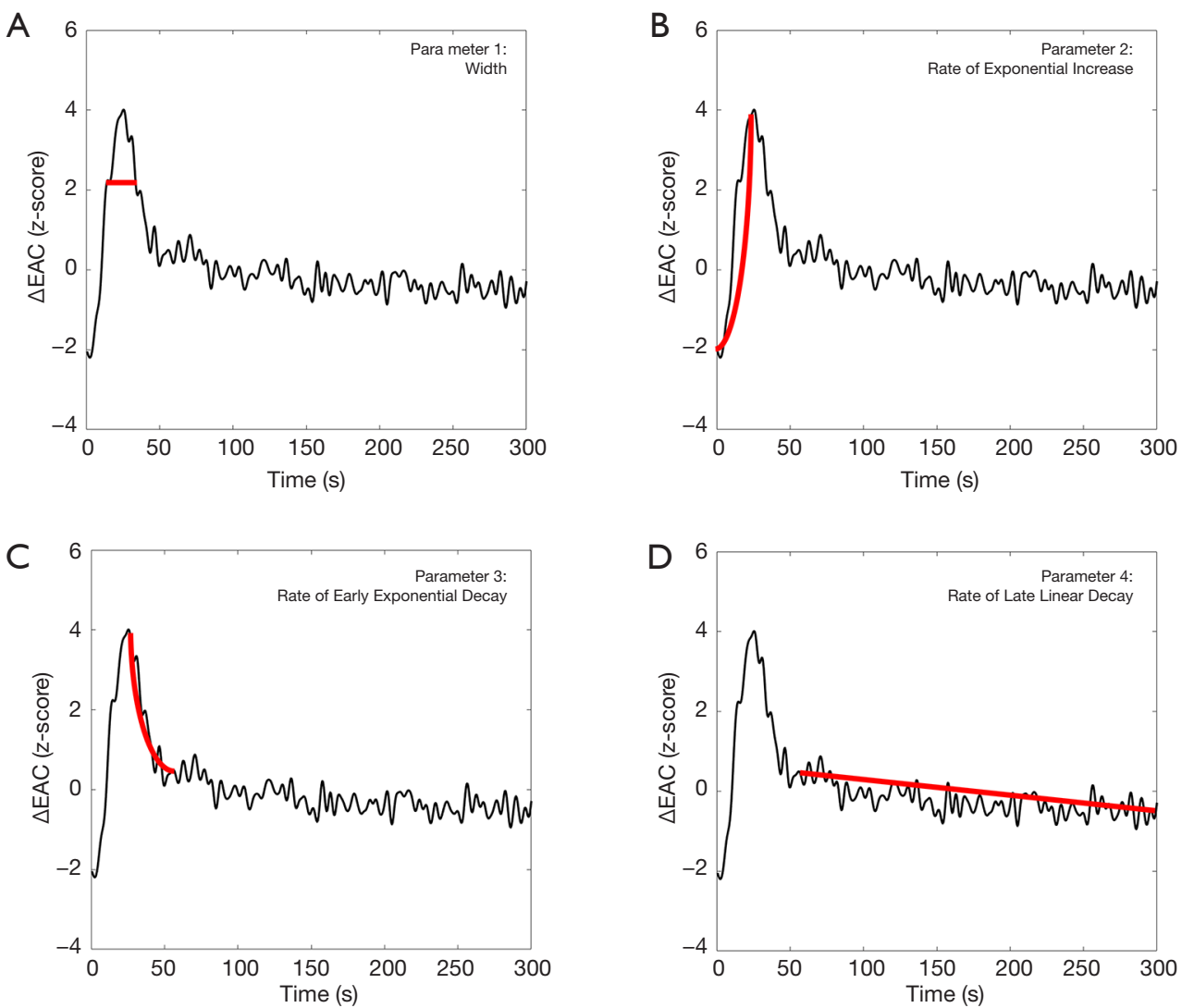

Figure 3 Example of a normalized (z-scored) EAC dynamic following ICG injection. Four parameters were extracted from each EAC curve: (A) width; (B) rate of early exponential increase; (C) rate of early exponential decay; and (D) rate of late linear decay. EAC, effective attenuation coefficient; ICG, indocyanine green.

\section{ICG's optical properties}

During the late linear decay, changes in the z-score of EAC in the TBI and non-TBI groups were merged together and the late linear decay between the red and the infrared were compared using the paired sample $t$-test. As mentioned in Sec. ICG's kinetic, changes of EAC were considered directly related to the ICG absorption properties changes.

\section{Results}

\section{ICG's kinetics}

Figure 4 shows averaged and normalized EAC temporal dynamics of TBI and non-TBI patients for different combinations of channel locations (left and right) and wavelengths (red and infrared).

The standard error of the mean is also reported. Clear differences between TBI and non-TBI ICG temporal dynamics are visible.

Figure 5 displays box-and-whisker plots of the various parameters for different combinations of channel locations (left and right), wavelengths (red and infrared) and groups (TBI and non-TBI patients).

Significant statistical differences between TBI and non-TBI patients $(\mathrm{P}<0.05)$ were obtained for the width parameter of the infrared signal in the right channel (t-score: $2.34, \mathrm{df}=8, \mathrm{P}=0.04$ ) and for the early exponential decay parameter of the InfraRed signal in the right channel (t-score: $3.12, \mathrm{df}=8, \mathrm{P}=0.01$ ). Although not statistically significant, a similar trend for the width (larger for TBI patients) and the rate of early exponential decay (smaller in absolute value for TBI patients) parameters were found for all combinations of channels and colors. On the contrary, the rate of exponential increase and rate of late linear decay did not show any significant differences between the two groups considered. 

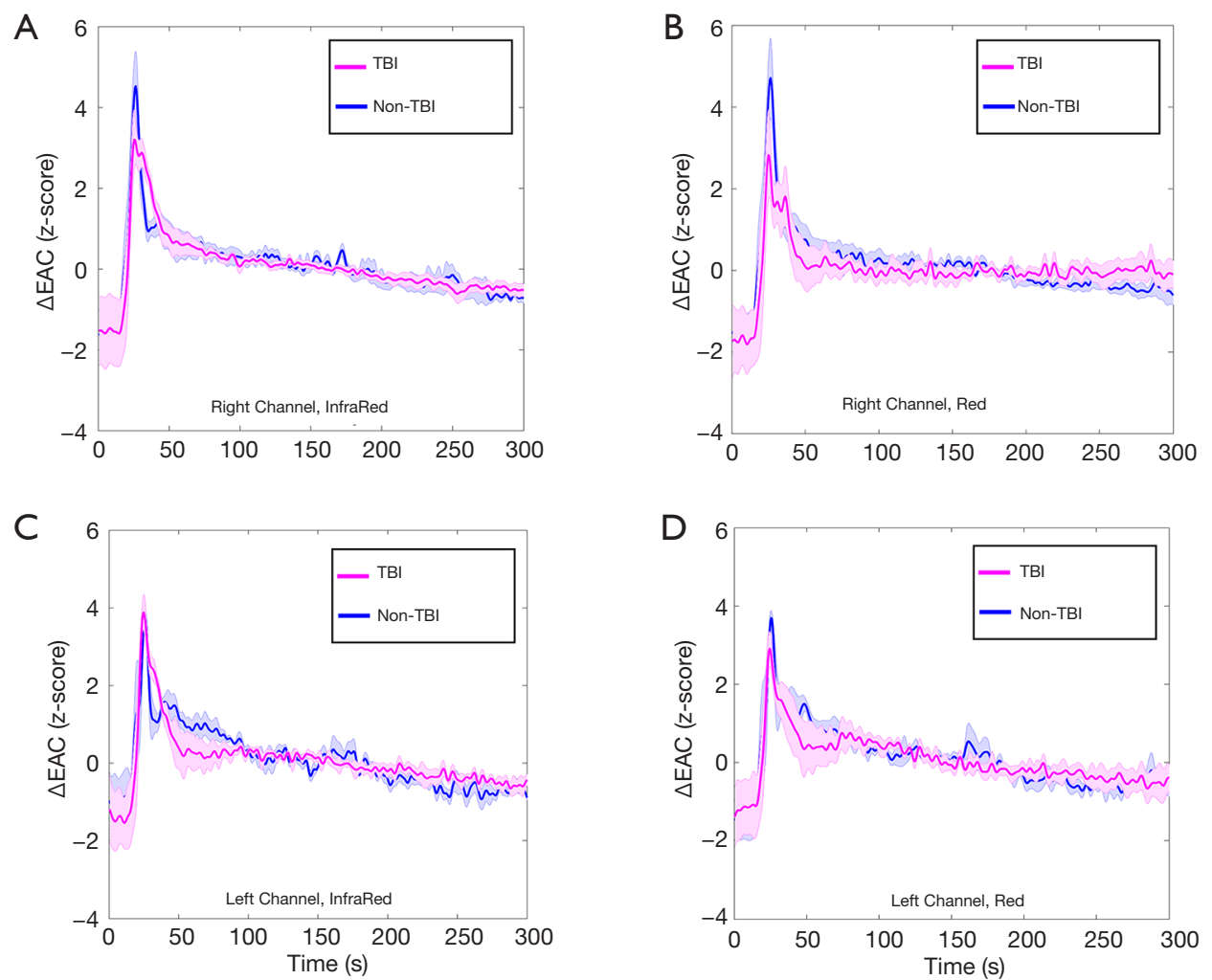

Figure 4 Average of the normalized (z-scored) EAC curves in TBI and non-TBI patients. (A) Right channel, infrared light; (B) right channel, red light; (C) left channel, infrared light; and (D) left channel, red light. EAC, effective attenuation coefficient; TBI, traumatic brain injury.

\section{ICG's optical properties}

In order to evaluate possible changes with time in the ICG optical properties, statistical comparisons (Student's paired t-tests) between the EAC curve parameters at each wavelength were performed. Interestingly, the rate of late linear decay was the only parameter showing statistically significant differences between red and infrared (t-score: $2.38, \mathrm{df}=9, \mathrm{P}=0.04$ ). Considering the temporal characteristics and the negative values of the rate of late linear decay, the result depicts a stronger increase in the attenuation in the InfraRed, probably associated with a slow modification to the ICG optical properties.

\section{Discussion}

\section{ICG's kinetics}

\section{First ICG's passage}

During the first ICG passage, in the right channels for the InfraRed color, the width and the early exponential decay of the EAC curve were significantly different between TBI and non-TBI patients. This can be related to reduced cerebral perfusion in the TBI group than in the non-TBI one, which slows the movement of the ICG bolus through the brain in the former as opposed to the latter. This result agrees with the literature where a broader curve of bolus passage due to vascular impairment is reported (35).

Similar trends in the width and early exponential decay were also seen in the left channels, however, the difference between TBI and non-TBI patients was not significant. The cerebral perfusion in TBI patients is inhomogeneous across the brain, therefore the different grades of width and early exponential decay between right and left channels could be the result of different grades of abnormal perfusion between hemispheres after a brain injury.

In both channels, there was no significant difference in the initial increase between the TBI and non-TBI groups. Previous studies in brain trauma and stroke patients reported changes of diffuse reflectance due to a delayed dye inflow related to vascular impairments (15,35-38). 
A
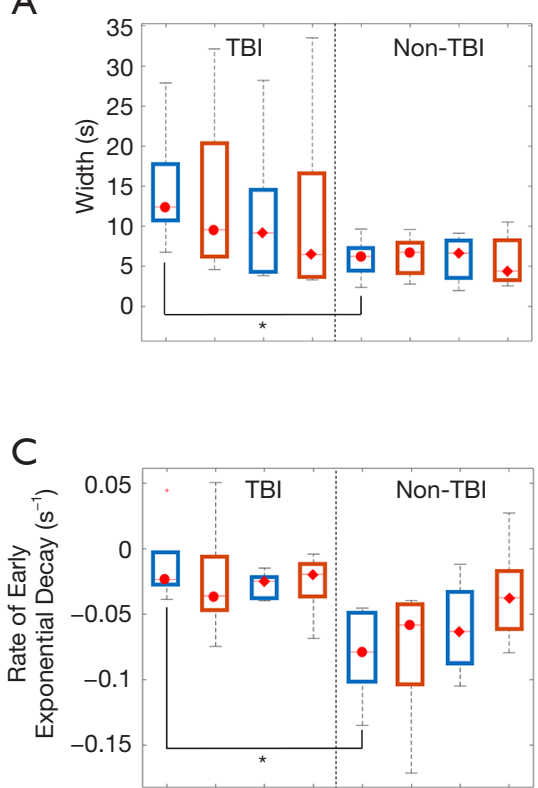

B
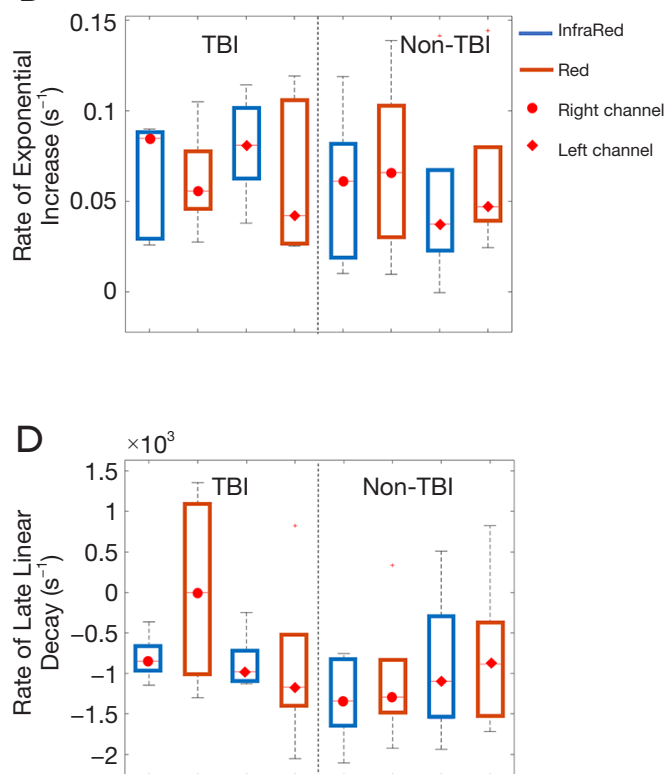

Figure 5 Box-and-whisker plots of the different parameters for different combinations of channel locations (left and right), wavelengths (red and infrared) and groups (TBI and non-TBI patients). The EAC curve parameters evaluated were (A) width; (B) rate of exponential increase; (C) rate of early exponential decay; and (D) rate of late linear decay. EAC, effective attenuation coefficient; TBI, traumatic brain injury.

However, there was no evidence of a similar delay in this study. The disagreement between the results herein exposed and those reported by previous studies can be related to the different optical analyses performed. In those aforementioned studies, the delay of ICG inflow was assessed through a comparison between intracranial (ICT) and extracranial tissues (ECT) or between hemispheres in the same patient. This was possible either because the vascular lesion of stroke patients could be identified in a specific hemisphere, or because the use of a time-domain (TD)-NIRS allowed for the separation of the ECT and ICT signals by plotting the distribution of time of flight of photons (DTOF). These two analyses were not possible in this study: in TBI patients a comparison between affected and non-affected hemispheres cannot easily be performed as the reduction of cerebral perfusion often affects different parts of the brain inconsistently; the optical analysis performed herein facilitated the relation of changes in optical signal according to depth, but not the separation of inflow into the ECT and the ICT as can be done using DTOF. It should be noted that, in agreement with our results, a direct comparison of values of initial increase between patients with vascular impairments and controls did not show a significant difference (37).

\section{ICG's retention}

Although, in both channels, the late linear decay was not significantly different between TBI and non-TBI patients, in the right channel, the trend suggests a higher level of photon absorption by ICG in the TBI group than in the non-TBI one.

In the minutes which followed the first ICG bolus passage, the continuous decrease of ICG concentration in the illuminated volume is related to the dilution of dye within the blood compartment and its uptake by the liver $(20,39)$. This process can be delayed in areas with BBB damage due to dye leakage into the interstitial tissue. In such a scenario, the dye outflows from the vascular system until its concentration in the vessels is lower than that in the interstitial tissue (34). These kinetics explain the higher concentration of the dye measured in the right channel of the TBI patients. The lack of statistical significance of the late linear decay in the right channels between the TBI and non-TBI groups may be related to the small sample size considered.

It should also be noted that the BBB damage may be present in some brain areas only and the ICG leakage would thus be limited to these areas alone (40). Therefore, some TBI patients may not have had BBB damage in 
their right hemisphere and so did not show a higher ICG concentration, with consequences for the statistical difference between the groups. Similarly, the different levels of EAC between right and left channels may be due to the inhomogeneity of BBB damage across the injured brain, which itself may have been present in the right rather than the left hemisphere in the TBI population examined.

\section{Extracranial trauma patients as controls}

A comparison between trauma patients could increase the accuracy of the analysis of brain abnormalities through ICG kinetics. To our knowledge, this is the first study that has analyzed ICG kinetics in the brain of TBI patients using patients who suffered extracranial trauma as controls.

After a trauma, liver perfusion can be reduced with consequences for ICG clearance $(41,42)$. Hence, a comparison between healthy subjects and TBI patients may mistake hepatic perfusion abnormalities for alterations in the brain, or the former can influence the values of the latter.

Furthermore, there can be a systemic inflammatory response following a trauma (43). As highlighted regarding liver perfusion abnormalities, a comparison between TBI and non-TBI patients helps to reduce the effects that an inflammatory response can have on the results obtained.

\section{ICG's optical properties}

During the late linear decay, there was a significant increase of ICG photon absorption at the InfraRed light compared to that at the Red light. This is in agreement with the changes in ICG absorption peak following binding with plasma components and explains why ICG kinetics could have been monitored using InfraRed rather than Red wavelengths $(19,23)$.

However, contrary to our hypothesis, there was no spectral stabilization a few seconds post-injection as the changes of ICG optical properties continued throughout the late linear decay. The longer time for ICG spectral stabilization to occur could be related to the need for the bolus to disperse into the bloodstream. This explanation is partially in agreement with a previous study that showed changes of optical density in vivo after 20-35 seconds from the ICG injection, due to the dye-blood intermixing process (44). It should also be noted that in that study, the authors calculated the ICG optical properties retrospectively at the beginning of the recording based on the spectrum of absorption once the dye was intermixed with blood (44).
The time of spectral stabilization may also have been prolonged by the formation of ICG aggregates while the ICG was dissolved in a water solution before it was injected. This is because the ICG aggregates cannot directly bind to plasma compounds, but they are progressively disaggregated into monomers by the binding process (23). The percentage of ICG aggregates, and so the time of spectral stabilization, would vary between patients because the time that the ICG stays in a pre-injection water solution is not constant. Furthermore, the different percentages of ICG aggregates between patients would affect the extent of any changes to ICG optical properties during the spectral stabilization, as ICG aggregates and monomers have different absorption peaks.

The small sample size considered in this study does not allow for an in-depth analysis of the changes in optical properties across individuals. However, considering the prolonged time for spectral stabilization to occur during in vivo experiments, future studies should investigate the variables connected to the changes of ICG absorption spectrum, as this may affect the accuracy of the kinetic analysis and measurements of the ICG concentration. Inaccuracies in the values of ICG concentration could be particularly relevant when the ICG concentration is used to retrieve absolute values of CBF and BBB damage (14). In addition, these results suggest that even if the dye kinetics can be mainly monitored using InfraRed wavelengths at approximately $810 \mathrm{~nm}$, analysis at multiple wavelengths should be preferred during in vivo experiments in order to track the changes of dye optical properties.

\section{Limitations}

\section{Signal-to-noise ratio}

A low signal-to-noise ratio may completely obscure the initial increase and the early exponential decay and severely compromise the late linear decay of an EAC curve. As a consequence, the quality of the recording related to that injection would be irreversibly affected.

The initial group of 15 TBI and 12 non-TBI patients had to be reduced to five TBI and five controls because of poor signal-to-noise ratios. This can be explained by the difficulties in acquiring data in challenging clinical environments due to multiple elements (e.g., illuminated environment, ecchymosis on the scalp, mechanical constraints) or the difficulties in clinicians using commercially available NIRS devices. In its current state, this level of quality control exclusion would not allow for direct translation of this technique into clinical practice. 


\section{Merged signal from different wavelengths}

The diffuse reflectance obtained at different wavelengths (810, 830, and $690,735 \mathrm{~nm}$, respectively) was merged together. This can be considered an approximation and may have interfered with the accuracy of the results.

\section{Fluorescence signal}

The fluorescence signal emitted by the ICG was not considered in this study.

Steinkellner et al. highlighted that in a system based on the level of dye photon absorption, its fluorescence signal should be considered as contamination (35). However, using a TD-NIRS device with and without fluorescence blocking filters, they reported a negligible effect of the fluorescence signal on the total number of photons, which can be considered as the optical signal measured in the study herein presented (35).

\section{Sedation}

Four of the TBI patients were sedated at the time of the measurement, while none of the controls were under sedation. The drugs used to sedate the TBI patients (e.g., propofol, midazolam) have a hypoperfusion effect on the CBF $(7,45)$. The different cerebral perfusion measured between the two groups could be partially explained by the effect of these drugs in the sedated patients. It should be noted that the different results between right and left channels suggests that the reduction of cerebral perfusion cannot be limited to the effects of the sedation alone.

\section{Comparison of the optical parameters measured with biomarkers of brain trauma}

The aims of this study were limited to the differences in optical signal between TBI and non-TBI patients, and no analysis was carried out to investigate correlation between the optical abnormities detected and other TBI biomarkers (e.g. hyperglycemia) (46).

Future multimodal monitoring studies should investigate how optical abnormalities are linked with other TBI biomarkers in order to better understand the pathogenetic mechanism responsible for these abnormalities and to include the optical results in TBI biosignatures for clinical practice $(10,47)$.

\section{Conclusions}

To conclude, using contrast-enhanced NIRS, we registered differing ICG kinetics between a TBI and a non-TBI group of patients. This difference can be related to abnormalities of cerebral perfusion and vascular permeability following a brain injury. Future larger studies should better quantify the changes in ICG kinetic after brain injury and test the efficacy of these values to enhance the treatments of TBI patients.

We also report difficulties in collecting high-quality optical data in clinical settings. This calls into question the viability of current commercially available NIRS devices for contrast-enhanced neuromonitoring for clinical purposes. Future work should aim to enhance the user-friendliness of these optical devices for applications of contrast-enhanced NIRS in clinical settings, similar to what has been done in other optical techniques $(48,49)$.

Contrary to our hypothesis, changes in ICG optical properties were seen for minutes after injection. Future research should aim to better define the pattern of changes of ICG optical properties during in vivo experiments to enhance the accuracy of contrast-enhanced NIRS with ICG.

\section{Acknowledgments}

The authors thank Mr. Joshua Deepak Veesa, Ms. Sandhya Trichinopoly Krishna and Mr. Zaeem Sultan for their help in the data collection.

Funding: This article presents independent research funded by the project "Brain Injury and Trauma Monitoring Using Advanced Photonics", financed by the European Union Horizon 2020 Research and Innovation Program, under grant agreement 675332, through the National Institute for Health Research Surgical Reconstruction and Microbiology Research Centre (NIHR SRMRC), partnership between University Hospitals Birmingham NHS Foundation Trust, the University of Birmingham, and the Royal Centre for Defence Medicine. The views expressed are those of the authors and not necessarily those of the NHS, the NIHR or the Department of Health. This work was also partially supported by Polish National Science Centre, Poland within the project number 2016/21/D/ST7/03454.

\section{Footnote}

Conflicts of Interest: All authors have completed the ICMJE uniform disclosure form (available at http://dx.doi. org/10.21037/qims-20-742). The authors report grants from European Union Horizon 2020 Research and Innovation Program, and from Polish National Science 
Centre, during the conduct of the study.

Ethical Statement: The study conforms to the Declaration of Helsinki (as revised in 2013) and was approved by East of England-Cambridge Central Research Ethics Board (Ref REC: 14/EE/0165; IRAS ID: 144979) and informed consent was taken from all the patients. Written informed consent was obtained from the patient for publication of this study and any accompanying images. A copy of the written consent is available for review by the Editor-in-Chief of this journal.

Open Access Statement: This is an Open Access article distributed in accordance with the Creative Commons Attribution-NonCommercial-NoDerivs 4.0 International License (CC BY-NC-ND 4.0), which permits the noncommercial replication and distribution of the article with the strict proviso that no changes or edits are made and the original work is properly cited (including links to both the formal publication through the relevant DOI and the license). See: https://creativecommons.org/licenses/by-nc-nd/4.0/.

\section{References}

1. James SL, Theadom A, Ellenbogen RG, Bannick MS, Montjoy-Venning W, Lucchesi LR, Abbasi N, Abdulkader R, Abraha HN, Adsuar JC, Afarideh M, Agrawal S, Ahmadi A, Ahmed MB, Aichour AN, Aichour I, Aichour MTE, Akinyemi RO, Akseer N, Alahdab F, Alebel A, Alghnam SA, Ali BA, Alsharif U, Altirkawi K, Andrei CL, Anjomshoa M, Ansari H, Ansha MG, Antonio CAT, Appiah SCY, Ariani F, Asefa NG, Asgedom SW, Atique S, Awasthi A, Ayala Quintanilla BP, Ayuk TB, Azzopardi PS, Badali H, Badawi A, Balalla S, Banstola A, BarkerCollo SL, Bärnighausen TW, Bedi N, Behzadifar M, Behzadifar M, Bekele BB, Belachew AB, Belay YA, Bennett DA, Bensenor IM, Berhane A, Beuran M, Bhalla A, Bhaumik S, Bhutta ZA, Biadgo B, Biffino M, Bijani A, Bililign N, Birungi C, Boufous S, Brazinova A, Brown AW, Car M, Cárdenas R, Carrero JJ, Carvalho F, CastañedaOrjuela CA, Catalá-López F, Chaiah Y, Champs AP, Chang JC, Choi JYJ, Christopher DJ, Cooper C, Crowe CS, Dandona L, Dandona R, Daryani A, Davitoiu DV, Degefa MG, Demoz GT, Deribe K, Djalalinia S, Do HP, Doku DT, Drake TM, Dubey M, Dubljanin E, ElKhatib Z, Ofori-Asenso R, Eskandarieh S, Esteghamati A, Esteghamati S, Faro A, Farzadfar F, Farzaei MH, Fereshtehnejad S-M, Fernandes E, Feyissa GT, Filip I,
Fischer F, Fukumoto T, Ganji M, Gankpe FG, Gebre AK, Gebrehiwot TT, Gezae KE, Gopalkrishna G, Goulart AC, Haagsma JA, Haj-Mirzaian A, Haj-Mirzaian A, Hamadeh RR, Hamidi S, Haro JM, Hassankhani H, Hassen HY, Havmoeller R, Hawley C, Hay SI, Hegazy MI, Hendrie D, Henok A, Hibstu DT, Hoffman HJ, Hole MK, Homaie Rad E, Hosseini SM, Hostiuc S, Hu G, Hussen MA, Ilesanmi OS, Irvani SSN, Jakovljevic M, Jayaraman S, Jha RP, Jonas JB, Jones KM, Jorjoran Shushtari Z, Jozwiak JJ, Jürisson M, Kabir A, Kahsay A, Kahssay M, Kalani R, Karch A, Kasaeian A, Kassa GM, Kassa TD, Kassa ZY, Kengne AP, Khader YS, Khafaie MA, Khalid N, Khalil I, Khan EA, Khan MS, Khang Y-H, Khazaie H, Khoja AT, Khubchandani J, Kiadaliri AA, Kim D, Kim Y-E, Kisa A, Koyanagi A, Krohn KJ, Kuate Defo B, Kucuk Bicer B, Kumar GA, Kumar M, Lalloo R, Lami FH, Lansingh VC, Laryea DO, Latifi A, Leshargie CT, Levi M, Li S, Liben ML, Lotufo PA, Lunevicius R, Mahotra NB, Majdan M, Majeed A, Malekzadeh R, Manda A-L, Mansournia MA, Massenburg BB, Mate KKV, Mehndiratta MM, Mehta V, Meles H, Melese A, Memiah PTN, Mendoza W, Mengistu G, Meretoja A, Meretoja TJ, Mestrovic T, Miazgowski T, Miller TR, Mini GK, Mirica A, Mirrakhimov EM, Moazen B, Mohammadi M, Molokhia M, Monasta L, Mondello S, Moosazadeh M, Moradi G, Moradi M, Moradi-Lakeh M, Moradinazar M, Morrison SD, Moschos MM, Mousavi SM, Murthy S, Musa KI, Mustafa G, Naghavi M, Naik G, Najafi F, Nangia V, Nascimento BR, Negoi I, Nguyen TH, Nichols E, Ningrum DNA, Nirayo YL, Nyasulu PS, Ogbo FA, Oh IH, Okoro A, Olagunju AT, Olagunju TO, Olivares PR, Otstavnov SS, Owolabi MO, P A M, Pakhale S, Pandey AR, Pesudovs K, Pinilla-Monsalve GD, Polinder S, Poustchi H, Prakash S, Qorbani M, Radfar A, Rafay A, Rafiei A, Rahimi-Movaghar A, RahimiMovaghar V, Rahman M, Rahman MA, Rai RK, Rajati F, Ram U, Rawaf DL, Rawaf S, Reiner RC, Reis C, Renzaho AMN, Resnikoff S, Rezaei S, Rezaeian S, Roever L, Ronfani L, Roshandel G, Roy N, Ruhago GM, Saddik B, Safari H, Safiri S, Sahraian MA, Salamati P, Saldanha RdF, Samy AM, Sanabria J, Santos JV, Santric Milicevic MMM, Sartorius B, Satpathy M, Savuon K, Schneider IJC, Schwebel DC, Sepanlou SG, Shabaninejad H, Shaikh MAA, Shams-Beyranvand M, Sharif M, Sharif-Alhoseini M, Shariful Islam SM, She J, Sheikh A, Shen J, Sheth KN, Shibuya K, Shiferaw MS, Shigematsu M, Shiri R, Shiue I, Shoman H, Siabani S, Siddiqi TJ, Silva JP, Silveira DGA, Sinha DN, Smith M, Soares Filho AM, Sobhani S, Soofi M, Soriano JB, Soyiri IN, Stein DJ, Stokes MA, Sufiyan MaB, 
Sunguya BF, Sunshine JE, Sykes BL, Szoeke CEI, TabarésSeisdedos R, Te Ao BJ, Tehrani-Banihashemi A, Tekle MG, Temsah MH, Temsah O, Topor-Madry R, TortajadaGirbés M, Tran BX, Tran KB, Tudor Car L, Ukwaja KN, Ullah I, Usman MS, Uthman OA, Valdez PR, Vasankari TJ, Venketasubramanian N, Violante FS, Wagnew FWS, Waheed Y, Wang YP, Weldegwergs KG, Werdecker A, Wijeratne T, Winkler AS, Wyper GMA, Yano Y, Yaseri M, Yasin YJ, Ye P, Yimer EM, Yip P, Yisma E, Yonemoto N, Yoon SJ, Yost MG, Younis MZ, Yousefifard M, Yu C, Zaidi Z, Zaman SB, Zamani M, Zenebe ZM, Zodpey S, Feigin VL, Vos T, Murray CJL. Global, regional, and national burden of traumatic brain injury and spinal cord injury, 1990-2016: a systematic analysis for the Global Burden of Disease Study 2016. Lancet Neurol 2019;18:56-87.

2. Andrews PJ, Sinclair HL, Rodriguez A, Harris BA, Battison CG, Rhodes JK, Murray GD, Eurotherm Trial C. Hypothermia for Intracranial Hypertension after Traumatic Brain Injury. N Engl J Med 2015;373:2403-12.

3. Cooper DJ, Rosenfeld JV, Murray L, Arabi YM, Davies AR, D'Urso P, Kossmann T, Ponsford J, Seppelt I, Reilly P, Wolfe R. Decompressive craniectomy in diffuse traumatic brain injury. N Engl J Med 2011;364:1493-502.

4. Hutchinson PJ, Kolias AG, Timofeev IS, Corteen EA, Czosnyka M, Timothy J, Anderson I, Bulters DO, Belli A, Eynon CA, Wadley J, Mendelow AD, Mitchell PM, Wilson MH, Critchley G, Sahuquillo J, Unterberg A, Servadei F, Teasdale GM, Pickard JD, Menon DK, Murray GD, Kirkpatrick PJ, Collaborators RET. Trial of Decompressive Craniectomy for Traumatic Intracranial Hypertension. N Engl J Med 2016;375:1119-30.

5. Chesnut RM, Temkin N, Carney N, Dikmen S, Rondina C, Videtta W, Petroni G, Lujan S, Pridgeon J, Barber J, Machamer J, Chaddock K, Celix JM, Cherner M, Hendrix T, Global Neurotrauma Research G. A trial of intracranial-pressure monitoring in traumatic brain injury. N Engl J Med 2012;367:2471-81.

6. Ganau M, Prisco L. Comment on "neuromonitoring in traumatic brain injury". Minerva Anestesiol 2013;79:310-1.

7. Moore EE, Feliciano DV, Mattox KL. Trauma, Eighth Edition. McGraw-Hill Education; 2017.

8. Vespa P, Bergsneider M, Hattori N, Wu HM, Huang SC, Martin NA, Glenn TC, McArthur DL, Hovda DA. Metabolic crisis without brain ischemia is common after traumatic brain injury: a combined microdialysis and positron emission tomography study. J Cereb Blood Flow Metab 2005;25:763-74.
9. Sahuquillo J, Poca MA, Arribas M, Garnacho A, Rubio E. Interhemispheric supratentorial intracranial pressure gradients in head-injured patients: are they clinically important? J Neurosurg 1999;90:16-26.

10. Ganau M, Syrmos N, Paris M, Ganau L, Ligarotti GKI, Moghaddamjou A, Chibbaro S, Soddu A, Ambu R, Prisco L. Current and Future Applications of Biomedical Engineering for Proteomic Profiling: Predictive Biomarkers in Neuro-Traumatology. Medicines (Basel, Switzerland) 2018;5:19.

11. Ghajar J. Traumatic brain injury. Lancet 2000;356:923-9.

12. Başkaya MK, Rao AM, Dogan A, Donaldson D, Dempsey RJ. The biphasic opening of the blood-brain barrier in the cortex and hippocampus after traumatic brain injury in rats. Neurosci Lett 1997;226:33-6.

13. Davies DJ, Su Z, Clancy MT, Lucas SJ, Dehghani H, Logan A, Belli A. Near-Infrared Spectroscopy in the Monitoring of Adult Traumatic Brain Injury: A Review. J Neurotrauma 2015;32:933-41.

14. Forcione M, Chiarelli AM, Davies DJ, Perpetuini D, Sawosz P, Merla A, Belli A. Cerebral perfusion and blood-brain barrier assessment in brain trauma using contrast-enhanced near-infrared spectroscopy with indocyanine green: A review. J Cereb Blood Flow Metab 2020;40:1586-98.

15. Weigl W, Milej D, Gerega A, Toczylowska B, Kacprzak M, Sawosz P, Botwicz M, Maniewski R, Mayzner-Zawadzka $\mathrm{E}$, Liebert A. Assessment of cerebral perfusion in posttraumatic brain injury patients with the use of ICG-bolus tracking method. Neuroimage 2014;85 Pt 1:555-65.

16. Liebert A, Milej D, Weigl W, Gerega A, Kacprzak M, Maniewski R. Fluorescence-based method for assessment of blood-brain barrier disruption. Conf Proc IEEE Eng Med Biol Soc 2013;2013:3040-2.

17. Milej D, Abdalmalak A, Desjardins L, Ahmed H, Lee TY, Diop M, St. Lawrence K. Quantification of blood-brain barrier permeability by dynamic contrast-enhanced NIRS. Sci Rep 2017;7:1702.

18. O'Connor JP, Tofts PS, Miles KA, Parkes LM, Thompson G, Jackson A. Dynamic contrast-enhanced imaging techniques: CT and MRI. Br J Radiol 2011;84 Spec No 2:S112-20.

19. Desmettre T, Devoisselle JM, Mordon S. Fluorescence properties and metabolic features of indocyanine green (ICG) as related to angiography. Surv Ophthalmol 2000;45:15-27.

20. Hope-Ross M, Yannuzzi LA, Gragoudas ES, Guyer DR, Slakter JS, Sorenson JA, Krupsky S, Orlock DA, 
Puliafito CA. Adverse reactions due to indocyanine green. Ophthalmology 1994;101:529-33.

21. Lee SS, Kim H, Sohn DK, Eom JB, Seo YS, Yoon HM, Choi Y. Indocyanine green-loaded injectable alginate hydrogel as a marker for precision cancer surgery. Quant Imaging Med Surg 2020;10:779-88.

22. Wang YG, Kim H, Mun S, Kim D, Choi Y. Indocyanine green-loaded perfluorocarbon nanoemulsions for bimodal (19)F-magnetic resonance/nearinfrared fluorescence imaging and subsequent phototherapy. Quant Imaging Med Surg 2013;3:132-40.

23. Landsman ML, Kwant G, Mook GA, Zijlstra WG. Lightabsorbing properties, stability, and spectral stabilization of indocyanine green. J Appl Physiol 1976;40:575-83.

24. Zhou JF, Chin MP, Schafer SA. Aggregation and degradation of indocyanine green. OE/LASE '94. SPIE; 1994.

25. Muckle TJ. Plasma proteins binding of indocyanine green. Biochem Med 1976;15:17-21.

26. Tripp MR, Cohen GM, Gerasch DA, Fox IJ. Effect of protein and electrolyte on the spectral stabilization of concentrated solutions of indocyanine green. Proc Soc Exp Biol Med 1973;143:879-83.

27. Chiarelli AM, Maclin EL, Low KA, Fantini S, Fabiani M, Gratton G. Low-resolution mapping of the effective attenuation coefficient of the human head: a multidistance approach applied to high-density optical recordings. Neurophotonics 2017;4:021103.

28. Chiarelli AM, Low KA, Maclin EL, Fletcher MA, Kong TS, Zimmerman B, Tan CH, Sutton BP, Fabiani M, Gratton G. The Optical Effective Attenuation Coefficient as an Informative Measure of Brain Health in Aging. Photonics 2019;6:79.

29. Scholkmann F, Zohdi H, Nasseri N, Wolf U. Absolute Values of Optical Properties (mua, mus, mueff and DPF) of Human Head Tissue: Dependence on Head Region and Individual. Adv Exp Med Biol 2018;1072:325-30.

30. Chiarelli AM, Perpetuini D, Filippini C, Cardone D, Merla A. Differential pathlength factor in continuous wave functional near-infrared spectroscopy: reducing hemoglobin's cross talk in high-density recordings. Neurophotonics 2019;6:035005.

31. Suzuki S, Takasaki S, Ozaki T, Kobayashi Y. Tissue oxygenation monitor using NIR spatially resolved spectroscopy. BiOS '99 International Biomedical Optics Symposium. SPIE; 1999.

32. Fantini S, Franceschini MA, Fishkin JB, Barbieri B, Gratton E. Quantitative determination of the absorption spectra of chromophores in strongly scattering media: a light-emitting-diode based technique. Appl Opt 1994;33:5204-13.

33. Bigio IJ, Fantini S. Quantitative Biomedical Optics: Theory, Methods, and Applications. Cambridge Texts in Biomedical Engineering. Cambridge: Cambridge University Press, 2016.

34. Cuenod CA, Balvay D. Perfusion and vascular permeability: basic concepts and measurement in DCE-CT and DCE-MRI. Diagn Interv Imaging 2013;94:1187-204.

35. Steinkellner O, Gruber C, Wabnitz H, Jelzow A, Steinbrink J, Fiebach JB, Macdonald R, Obrig H. Optical bedside monitoring of cerebral perfusion: technological and methodological advances applied in a study on acute ischemic stroke. J Biomed Opt 2010;15:061708.

36. Liebert A, Wabnitz H, Steinbrink J, Moller M, Macdonald R, Rinneberg H, Villringer A, Obrig H. Bed-side assessment of cerebral perfusion in stroke patients based on optical monitoring of a dye bolus by time-resolved diffuse reflectance. Neuroimage 2005;24:426-35.

37. Terborg C, Bramer S, Harscher S, Simon M, Witte OW. Bedside assessment of cerebral perfusion reductions in patients with acute ischaemic stroke by near-infrared spectroscopy and indocyanine green. J Neurol Neurosurg Psychiatry 2004;75:38-42.

38. Terborg C, Groschel K, Petrovitch A, Ringer T, Schnaudigel S, Witte OW, Kastrup A. Noninvasive assessment of cerebral perfusion and oxygenation in acute ischemic stroke by near-infrared spectroscopy. Eur Neurol 2009;62:338-43.

39. Hopton P, Walsh TS, Lee A. Measurement of cerebral blood volume using near-infrared spectroscopy and indocyanine green elimination. J Appl Physiol (1985) 1999;87:1981-7.

40. Ergin A, Wang M, Zhang J, Bigio I, Joshi S. Noninvasive in vivo optical assessment of blood brain barrier permeability and brain tissue drug deposition in rabbits. J Biomed Opt 2012;17:057008.

41. Geneve J, Le Dinh T, Brouard A, Bails M, Segrestaa JM, Caulin C. Changes in indocyanine green kinetics after the administration of enalapril to healthy subjects. Br J Clin Pharmacol 1990;30:297-300.

42. Vos JJ, Wietasch JK, Absalom AR, Hendriks HG, Scheeren TW. Green light for liver function monitoring using indocyanine green? An overview of current clinical applications. Anaesthesia 2014;69:1364-76.

43. Hazeldine J, Naumann DN, Toman E, Davies D, Bishop 
JRB, Su Z, Hampson P, Dinsdale RJ, Crombie N, Duggal NA, Harrison P, Belli A, Lord JM. Prehospital immune responses and development of multiple organ dysfunction syndrome following traumatic injury: A prospective cohort study. PLoS Med 2017;14:e1002338.

44. Mudra R, Muroi C, Niederer P, Keller E. Near-infrared spectroscopy extended with indocyanine green dye dilution for cerebral blood flow measurement: Median values in healthy volunteers. Opto-Electronics Review 2008; 16:297-308.

45. Katzung BG, Trevor AJ. Basic \& clinical pharmacology. Thirteenth ed. New York: McGraw-Hill Education; 2015.

46. Prisco L, Iscra F, Ganau M, Berlot G. Early predictive factors on mortality in head injured patients: a retrospective analysis of 112 traumatic brain injured patients. J Neurosurg Sci 2012;56:131-6.

Cite this article as: Forcione M, Yakoub KM, Chiarelli AM, Perpetuini D, Merla A, Sun R, Sawosz P, Belli A, Davies DJ. Dynamic contrast-enhanced near-infrared spectroscopy using indocyanine green on moderate and severe traumatic brain injury: a prospective observational study. Quant Imaging Med Surg 2020;10(11):2085-2097. doi: 10.21037/qims-20-742
47. Ganau L, Prisco L, Ligarotti GKI, Ambu R, Ganau M. Understanding the Pathological Basis of Neurological Diseases Through Diagnostic Platforms Based on Innovations in Biomedical Engineering: New Concepts and Theranostics Perspectives. Medicines (Basel) 2018;5:22.

48. Shu X, Beckmann L, Wang Y, Rubinoff I, Lucy K, Ishikawa H, Wollstein G, Fawzi AA, Schuman JS, Kuranov RV, Zhang HF. Designing visible-light optical coherence tomography towards clinics. Quant Imaging Med Surg 2019;9:769-81.

49. Wang Y, Zhan Y, Harris LM, Khan S, Xia J. A portable three-dimensional photoacoustic tomography system for imaging of chronic foot ulcers. Quant Imaging Med Surg 2019;9:799-806. 